\title{
Hormigón ligero con agregado reciclado de EVA para atenuación del ruido de impacto
}

\section{Lightweight concrete with EVA recycled aggregate for impact noise attenuation}

\author{
B. F. Tutikian(*), M. F. O. Nunes ${ }^{(*, * *)}$, L. C. Leal(*), L. Marquetto(*)
}

Recepción/Received: 18-XI-11

Aceptación/Accepted: 26-III-12

Publicado online/Online publishing: 31-VII-12

\section{RESUMEN}

La propuesta de este estudio consiste en la evaluación del desempeño acústico del hormigón ligero con residuos de ethylene vinyl acetate copolymer (EVA) para la reducción del ruido de impacto en pisos. Fueron evaluados tres tipos de hormigón con tres trazas diferentes. El método adoptado incluye la caracterización de la absorción de agua, del índice de vacíos y de la densidad en las muestras. El estudio experimental del ruido de impacto siguió las recomendaciones de ISO 140 . Los resultados indican que el hormigón ligero con EVA reciclado puede reducir el nivel de ruido de impacto en hasta $15 \mathrm{~dB}$ y que el porcentaje más alto de árido grueso de EVA no aumenta el desempeño acústico.

Palabras clave: hormigón; polímero; caracterización.
SUMMARY

The purpose of this study is to evaluate the acoustic performance of lightweight concrete with ethylene vinyl acetate copolymer (EVA) residues to reduce impact noise on floors. Three types of concrete with three different mix proportions were evaluated. The method adopted includes the characterization of water absorption, voids and density of the samples. The experimental study of noise impact followed the procedures of ISO 140. The results indicate that the lightweight concrete with EVA recycled aggregate can reduce impact noise levels by up to $15 d B$ and the highest percentage of coarse aggregate EVA does not entail a higher acoustic performance.

Keywords: concrete; polymer; characterization.

\footnotetext{
(*) Universidad do Rio dos Sinos, São Leopoldo, RS (Río Grande del Sur, Brazil).

(**) Universidad de Caxias do Sul, RS (Río Grande del Sur, Brazil).
} 


\section{INTRODUCTION}

Lightweight concrete is characterized by the use of lowdensity aggregates with high amount of voids between the particles or by the replacement of solid material by air, which can be achieved through the incorporation of air or foam, or a low specific mass can be achieved producing concrete without fines.

The low density of the mixture is achieved due to the use of lightweight aggregates which produces specific characteristics such as low density, ranging from $300 \mathrm{~kg} / \mathrm{m}^{3}$ to $1.800 \mathrm{~kg} / \mathrm{m}^{3}$ and compressive strength, ranging from $0.3 \mathrm{MPa}$ to $40 \mathrm{MPa}$. The coarse and fine aggregates are considered lightweight when their density is less than $1.120 \mathrm{~kg} / \mathrm{m}^{3}$ and greater than $880 \mathrm{~kg} / \mathrm{m}^{3}$, respectively (1).

These features indicate that the lightweight aggregate can be used for acoustic performance qualification in buildings, especially for the impact noise isolation of floors.

The noise in buildings can spread through the air, the airborne noise, or through the structures themselves, defined as impact noise. The impact noise is produced by percussion of solid bodies on a floor, transmitted through the structure and re-radiated by it into the air (e.g. falling objects, footsteps, hammering, percussion instruments, etc. (2).

The transmission through the structure is the shortest and most direct path transmission of impact noise. A hard floor that deforms slightly before the impact, loads and transmits the noise in a very short time whilst on a deformable floor the transmission time is greater and therefore, the amplitude transmission of impact force is smaller. In both cases the sound response is very distinct, and it is produced higher sound frequencies in the first aspect and lower in the second (3).

Bistafa (4) explains that even in thick and dense concrete slabs, impact noise level is high. Even if the sound transmission level is reduced by increasing thickness, such a solution is not adopted due to lack of efficiency and to increasing costs of material and structure weight.

Brazilian standard ABNT NRB 15575-3 (5) characterizes residential building floors as the element responsible for providing sound insulation, depending on use of distinct housing units or between rooms of the same unit, when for the night's rest, domestic leisure or intellectual work. Table 1 shows the performance rating criteria recommended for the standardized weighted sound impact levels ( $\left.L_{n T, w}^{\prime}\right)$ provided by the structural slab.

Layers with deformable elastic materials are very important as the first energy absorption. Moreover, combined or not with these layers, the floating floor presents the most satisfactory results (3).

Floating floors are a commonly used solution to reduce impact noise. It involves placing resilient material between the structural concrete slab and the sub floor, which can improve by up to $20 \mathrm{~dB}$ isolation from the sounds of impact. Insulators (resilient materials) may be rubber pads, cork and other materials evenly distributed, or plates of glass wool, rock wool, expanded polystyrene, among others (4).

Experimental studies have contributed to develope products whose performance can be compared to traditional materials available. Studies evaluated and compared materials using different waste types in mitigating impact noise on floors. Materials using waste types such as carpets (6), recycled rubber $(7,8)$, coconut fiber (9) and footwear industry waste with PU and ethylene vinyl acetate copolymer (EVA) (10-12) provide performance similar to glass wool. The materials were used in floating floor system, as a layer between the sub floor and structural concrete slab.

The purpose of this study is to evaluate the acoustic performance of a new material with ethylene vinyl acetate copolymer (EVA) recycled aggregate replacing conventional coarse aggregate in the production of lightweight concrete sub floor for residential buildings.

Table 1

Brazilian standard ABNT NBR 15575-3 recommended classification criteria for the acoustic performance for residential floors (5).

\begin{tabular}{|c|c|c|}
\hline Type & L'nT,w (dB) & Performance classification \\
\hline $\begin{array}{c}\text { Intermediate floor slab or other structural element, with or without sub floor, without } \\
\text { acoustic insulation }\end{array}$ & 66 a/to 80 & $\mathrm{M}$ (minimum) \\
\hline \multirow{2}{*}{$\begin{array}{l}\text { Intermediate floor slab or other structural element, with or without sub floor, with } \\
\text { acoustic insulation }\end{array}$} & 56 a/to 65 & I (/intermediate) \\
\hline & $\leq 55$ & S (superior) \\
\hline \multirow{3}{*}{ Roof terrace for collective use } & 56 a/to 65 & $\mathrm{M}$ (minimum) \\
\hline & 46 a/to 65 & I (intermediate) \\
\hline & $\leq 45$ & S (superior) \\
\hline
\end{tabular}




\section{MATERIALS AND METHODS}

\subsection{Materials}

In this study two types of coarse aggregate were used: natural and industrially produced. The natural coarse aggregate comes from granite rock, with maximum characteristic dimension of $9.5 \mathrm{~mm}$. The choice for this type of natural aggregate was due to similar EVA coarse aggregate grain size. The natural aggregate was previously washed, dried in an oven until mass constancy and kept packed in sealed plastic containers until the moment to be used.

Characterization of aggregates of EVA was performed according to methods specified by ISO 6782 (13). However, adjustments were made to enable the testing.

In the granulometric analysis test conducted according to ISO 6274 (14), the samples showed mass difference during weighing of the fractions retained in the sieves according to the weight of the total sample. The solution was to weigh both the total sample and the fractions only after mass constancy, being held at a temperature of $60^{\circ} \mathrm{C}(13)$.

In the EVA aggregate specific mass test, which followed ISO 6783 (15), the samples floated when immersed, so it was necessary to make an adjustment to keep the EVA aggregate underwater. It was necessary to install a barrier screen at the test apparatus, in order to prevent the material floated to the surface.

The coarse EVA aggregate used in this study comes from two types of recycling processes. The coarse aggregate EVA, named EVA1, is an artificial aggregate obtained from an industrial process that removes the dust generated in the grinding step of the waste generated by EVA footwear industry.

The coarse aggregate EVA, named EVA2, is obtained through an artisanal recycling process of waste of footwear companies and ground and wrapped for sale. In the production of this aggregate it is not given the treatment to the EVA powder generated during the process. The choice for this type of EVA coarse aggregate is based on the possibility of comparing two different samples of lightweight aggregates.

The concrete was cast with three different types of mortar. The mix proportion 1:1:4 features $80 \%$ of coarse aggregate and $20 \%$ of fine aggregate; the mix proportion $1: 1.5: 3.5$ is composed by $70 \%$ of coarse aggregate and $30 \%$ of fine aggregate; and the $1: 2: 3$ mixture contains $60 \%$ of coarse aggregate and $40 \%$ of fine aggregate. The mix proportions samples and designations adopted for each sample are presented in Table 2, resulting in nine samples of concrete tested.

Table 2

Concrete proportions prepared in laboratory.

\begin{tabular}{|c|c|c|}
\hline Aggregate & Mixtures & Designation \\
\hline \multirow{3}{*}{ Natural } & $1: 1: 4$ & $\mathrm{Na}$ \\
\cline { 2 - 3 } & $1: 1.5: 3.5$ & $\mathrm{Nb}$ \\
\cline { 2 - 3 } & $1: 2: 3$ & $\mathrm{Nc}$ \\
\hline \multirow{3}{*}{ EVA 1 } & $1: 1: 4$ & $\mathrm{E} 1 \mathrm{a}$ \\
\cline { 2 - 3 } & $1: 1.5: 3.5$ & $\mathrm{E} 1 \mathrm{~b}$ \\
\cline { 2 - 3 } & $1: 2: 3$ & $\mathrm{E} 1 \mathrm{c}$ \\
\hline \multirow{3}{*}{ EVA2 } & $1: 1: 4$ & $\mathrm{E} 2 \mathrm{a}$ \\
\cline { 2 - 3 } & $1: 1.5: 3.5$ & $\mathrm{E} 2 \mathrm{~b}$ \\
\cline { 2 - 3 } & $1: 2: 3$ & $\mathrm{E} 2 \mathrm{c}$ \\
\hline
\end{tabular}

\subsection{Water absorption, voids and specific mass}

The methodology adopted in this work follows procedures in accordance with ISO 6783 (15). The tests were made after 28 days of curing with two specimens with $100 \mathrm{~mm}$ in diameter and $200 \mathrm{~mm}$ in height.

The specimens were dried in an oven at $60^{\circ} \mathrm{C}$ until they reached mass constancy. The temperature was chosen to preserve the characteristics of EVA aggregates. After that, the specimens were kept submerged in water during 72 hours in a climatized room to a temperature of $23^{\circ} \mathrm{C} \pm 2{ }^{\circ} \mathrm{C}$. Afterwards, they were boiled for five hours.

\subsection{Acoustic performance}

To determine the weighted normalized impact sound pressure levels the specimens were tested using the method described by ISO 140-7 (16) which determines procedures for field measurements, and the ISO 717-2 (17) which defines the method of obtaining the singlenumber for impact noise on floors.

The tests sounds were generated with a normalised tapping machine Bruel \& Kjaer type 3207. The noises were generated in the source room, on the floor immediately above the receiving room, where three measurements were carried out with the sound level analyzer Quest, in third octave bands in the frequency range $100 \mathrm{~Hz}$ to $3150 \mathrm{~Hz}$ in three different positions.

The rooms have hard surfaces and are separated by a structural concrete slab with a thickness of $100 \mathrm{~mm}$ and built with masonry walls coated with plaster and paint. Both rooms dimensions are $4.64 \mathrm{~m} \times 3.5 \mathrm{~m} \times 2.76 \mathrm{~m}$, with a total area of $16.24 \mathrm{~m}^{2}$ and a volume of $44.82 \mathrm{~m}^{3}$. The sample tested was $1 \mathrm{~m}^{2}$ which consisted of four 
plates of $50 \mathrm{~cm} \times 50 \mathrm{~cm} \times 3 \mathrm{~cm}$. Thus, the results are valid for the acoustic performance comparisons among the samples, and can reveal the influence of aggregate recycled EVA in the acoustic insulation of floors.

The results treatment consists in obtaining single-number quantities for the standard impact sound levels pressure $\left(L_{n T}^{\prime}\right)$. This number results from the comparison of the sound spectrum curve measured and the reference curve by ISO 717-2 (17), which expresses the acoustic performance in $\mathrm{dB}$ of the floor system tested. Nine samples prepared in laboratory placed on an uncoated concrete slab were tested.

\section{RESULTS AND DISCUSSION}

\subsection{Materials characterization}

The cement used was the CPV-ARI, due to its high initial resistance and the need to quickly unmold the material molded into plates with small thickness compared to width and length. The mechanical properties of cement are shown in Table 3.

It is observed that the properties of the cement CPV-ARI meet the regulatory requirements, approving the material for testing.

Table 4 presents the physical characteristics of the used aggregates, including natural, artificial, fine and coarse.
According to Table 4, it is observed that the EVA1 aggregate presents bulk density corresponding to $6 \%$ of the bulk density of the natural coarse aggregate; in contrast, for the EVA2 aggregate this difference is $7 \%$. Similar relationships are observed for the dry surface aggregate, showing that EVA aggregates do with the density far below the natural aggregates, as it was expected.

The unit mass was lower for EVA aggregates as well. The EVA1 presented unit mass corresponding to $8.5 \%$ of unit mass of natural coarse aggregate, while the EVA2 presented unit mass corresponding to $5 \%$ of unit mass of natural coarse aggregate. That is, the low mass of the EVA also occurs in the voids presence.

The EVA1 aggregate presented fineness modulus 4\% lower than the natural coarse aggregate while the EVA2 aggregate of fineness modulus was $12 \%$ lower than the natural coarse aggregate. As they have the same maximum characteristic dimension and distribution of the particles, it is concluded that the aggregates are similar in size and distribution.

However, it is observed that the EVA aggregates require more water to wet their grain than the natural aggregates do and the EVA2 needs more water to wet their grain than the EVA1, whereas EVA1 and EVA2 have a water absorption 42.5 and 44.5 times higher, respectively, than the natural coarse aggregate. However, the EVA2 absorption of water was $5 \%$ higher than the EVA1.

Table 3

Mechanical properties of the cement CPV-ARI.

\begin{tabular}{|c|c|c|c|}
\hline \multicolumn{2}{|l|}{ Properties } & Results & Limit of ISO $6782(13)$ \\
\hline \multicolumn{2}{|c|}{ Residue on sieve \# $75 \mu \mathrm{m}$ - ISO 3310 (18) } & $0.84 \%$ & $\leq 6 \%$ \\
\hline \multicolumn{2}{|c|}{ Setting time beginning - ISO 9597 (19) } & $3: 28 \mathrm{~h}$ & $\geq 1 \mathrm{~h}$ \\
\hline \multicolumn{2}{|c|}{ Setting time end - ISO 9597 (19) } & $5: 35 \mathrm{~h}$ & $\leq 10 \mathrm{~h}$ \\
\hline \multirow{3}{*}{ Compressive strength - ISO 1920 (20) } & 1day & $17.4 \mathrm{MPa}$ & $\geq 14 \mathrm{MPa}$ \\
\hline & 3 days & $25.8 \mathrm{MPa}$ & $\geq 24 \mathrm{MPa}$ \\
\hline & 7 days & $34.1 \mathrm{MPa}$ & $\geq 34 \mathrm{MPa}$ \\
\hline
\end{tabular}

Table 4

Physical characterization of aggregates.

\begin{tabular}{|c|c|c|c|c|c|}
\hline \multicolumn{2}{|c|}{ Aggregate characterization } & $\begin{array}{l}\text { Natural fine } \\
\text { aggregate }\end{array}$ & $\begin{array}{c}\text { Natural coarse } \\
\text { aggregate }\end{array}$ & EVA 1 & EVA 2 \\
\hline \multicolumn{2}{|c|}{ Maximum dimension characteristic ISO 6274 (14) } & $9.5 \mathrm{~mm}$ & $9.5 \mathrm{~mm}$ & $9.5 \mathrm{~mm}$ & $9.5 \mathrm{~mm}$ \\
\hline \multicolumn{2}{|c|}{ Modulus of fineness ISO 6274 (14) } & 2.92 & 2.83 & 2.71 & 2.48 \\
\hline \multicolumn{2}{|c|}{ Water absorption ISO 6783 (15) } & $0.3 \%$ & $1.3 \%$ & $55.2 \%$ & $57.8 \%$ \\
\hline \multirow{3}{*}{ Bulk density ISO 6783 (15) } & Apparent & $2.53 \mathrm{~g} / \mathrm{cm}^{3}$ & $2.98 \mathrm{~g} / \mathrm{cm}^{3}$ & $0.17 \mathrm{~g} / \mathrm{cm}^{3}$ & $0.21 \mathrm{~g} / \mathrm{cm}^{3}$ \\
\hline & S.S.S & $2.51 \mathrm{~g} / \mathrm{cm}^{3}$ & $2.90 \mathrm{~g} / \mathrm{cm}^{3}$ & $0.26 \mathrm{~g} / \mathrm{cm}^{3}$ & $0.33 \mathrm{~g} / \mathrm{cm}^{3}$ \\
\hline & Dry aggregate & $2.49 \mathrm{~g} / \mathrm{cm}^{3}$ & $2.87 \mathrm{~g} / \mathrm{cm}^{3}$ & $0.19 \mathrm{~g} / \mathrm{cm}^{3}$ & $0.24 \mathrm{~g} / \mathrm{cm}^{3}$ \\
\hline \multicolumn{2}{|c|}{ Unit mass - ISO $3310(18)$} & $1.54 \mathrm{~g} / \mathrm{cm}^{3}$ & $1.65 \mathrm{~g} / \mathrm{cm}^{3}$ & $0.14 \mathrm{~g} / \mathrm{cm}^{3}$ & $0.08 \mathrm{~g} / \mathrm{cm}^{3}$ \\
\hline
\end{tabular}




\subsection{Water absorption, voids and bulk density of concretes}

Table 5 presents the results of water absorption, voids and bulk density of concretes.

It is observed that, in general, the concrete with EVA aggregates showed higher water absorption, higher amounts of voids and lower bulk density be it dry, saturated and real.

It is noticed that most of the absorption occurs in trace 1:1:4, molded with EVA2, which had the highest water absorption. This sample had water absorption 8.9 times greater than the absorption of the reference trace and 2.2 times greater than the trace with EVA1. Parallel to it, the sample that showed the highest percentage of voids was the 1:1:4 with EVA2, with a percentage of $38.56 \%$.

It was also noted that the average bulk density of EVA1 concretes corresponds to $46 \%$ of the bulk density of the trace reference, whereas the average bulk density of EVA2 concretes is $63 \%$.

Among the concretes with EVA, EVA1 showed more satisfactory results than EVA2, with lower water absorption and voids. In terms of bulk density, the samples with EVA1 had lower values than EVA2.

In addition, the lower the content of mortar, that is, the greater amount of coarse aggregate in relation to the fine aggregate, the lower values of bulk density. For example, the trace with EVA1 1:1:4 has a dry bulk density 15\% lower than the trace with the same materials $1: 1.5: 3.5$ and $18 \%$ than the characteristic $1: 2: 3$.

\subsection{Acoustic performance}

Figure 1 combines the results of all samples tested with their respective values of L'nT, pointing out that the sample called slab corresponds to the values measured under the slab of the receiving room, without the use of material between the slab and the tapping machine.

Table 5

Water absorption, voids and bulk density of concretes.

\begin{tabular}{|c|c|c|c|c|c|}
\hline Sample & Water absorption (\%) & Voids (\%) & Dry bulk density $\mathbf{~} / \mathbf{d m}^{\mathbf{3}}$ & Saturated bulk density $\mathbf{~} / \mathbf{d m}^{\mathbf{3}}$ & ${\text { Bulk density } \mathbf{~} / \mathbf{d m}^{\mathbf{3}}}$ \\
\hline $\mathrm{Na}$ & 4.87 & 11.53 & 2.370 & 2.480 & 2.670 \\
\hline $\mathrm{Nb}$ & 3.11 & 7.53 & 2.420 & 2.500 & 2.620 \\
\hline $\mathrm{Nc}$ & 2.40 & 5.75 & 2.400 & 2.460 & 2.550 \\
\hline $\mathrm{E} 1 \mathrm{a}$ & 19.65 & 17.58 & 890 & 1.070 & 1.080 \\
\hline $\mathrm{E} 1 \mathrm{~b}$ & 17.08 & 17.76 & 1.040 & 1.220 & 1.260 \\
\hline $\mathrm{E} 1 \mathrm{c}$ & 12.28 & 13.33 & 1.090 & 1.270 & 1.260 \\
\hline $\mathrm{E} 2 \mathrm{a}$ & 43.54 & 38.56 & 890 & 1.450 & 1.440 \\
\hline $\mathrm{E} 2 \mathrm{~b}$ & 29.53 & 32.95 & 1.120 & 1.580 & 1.660 \\
\hline $\mathrm{E} 2 \mathrm{c}$ & 20.77 & 27.11 & 1.310 & & 1.800 \\
\hline
\end{tabular}

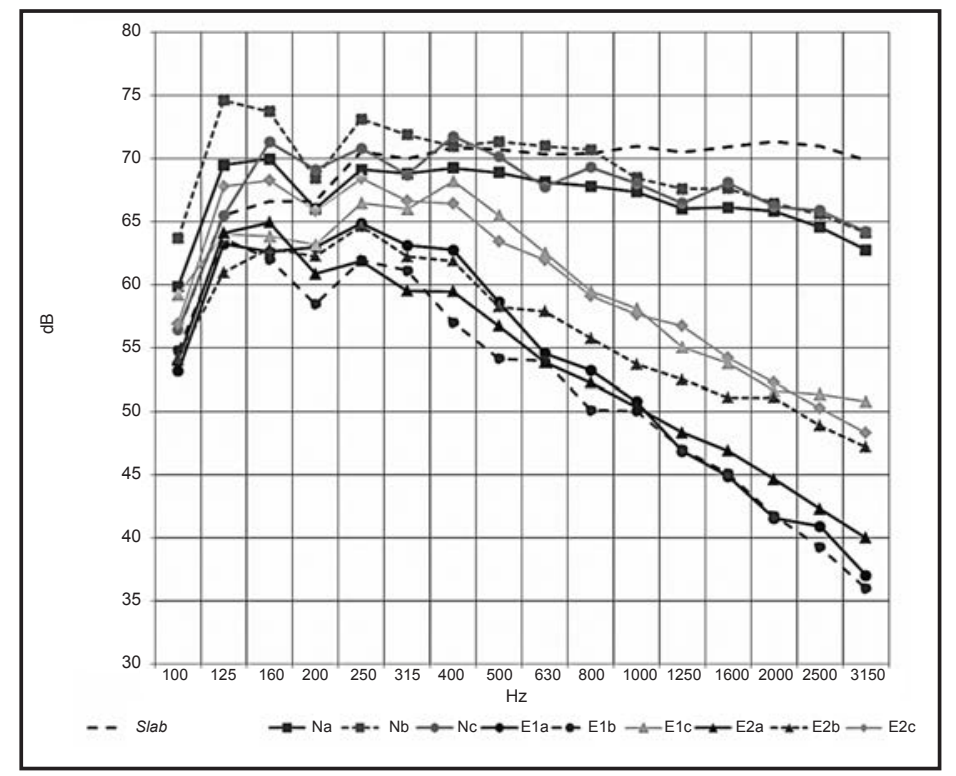

Figure 1. L'nT sound pressure levels by frequency. 


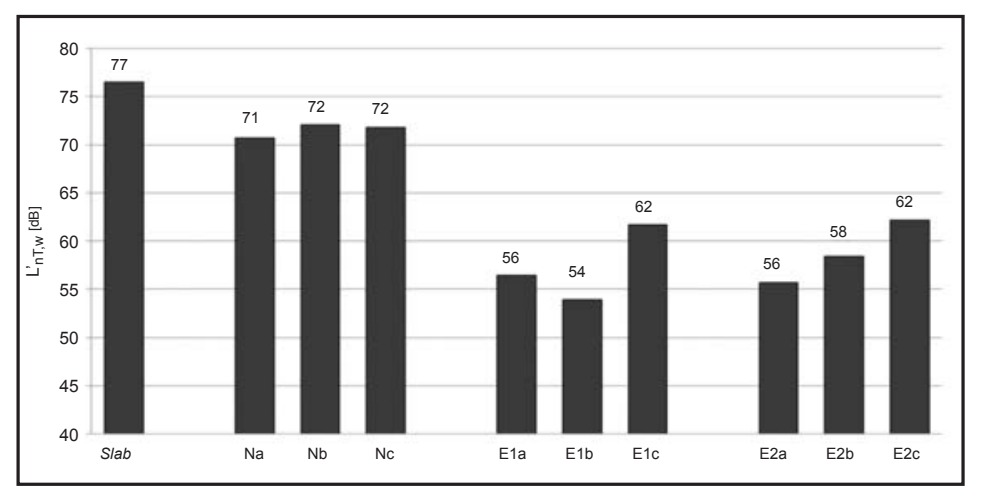

Figure 2. Weighted standardized impact sound pressure level of samples.

The results can be divided into three distinct groups in relation to coarse aggregate mix proportions.

The samples made with natural coarse aggregate had the highest measured values, and, among them, the lowest value was the sample 1:1:4 (Na). The frequencies up to $160 \mathrm{~Hz}$ with natural aggregate samples showed higher values than those of simple slab, featuring those frequencies near resonance frequency, with the simultaneous vibration of the set, which leads to the amplification of sound. In this case, there is a solidarity movement and phase composition of the sample and the concrete slab, stimulated by low frequency of $160 \mathrm{~Hz}$.

The second group, formed by the specimens made from EVA1 aggregate, presented intermediate values of sound pressure levels at similar frequencies from $315 \mathrm{~Hz}$, except for trace 1:2:3 (E1C), which showed higher values. The best results were obtained for specimens prepared on the basis of EVA with a higher proportion of coarse aggregate, i.e., with traces of $1: 1: 4$ and $1: 1.5: 3.5$, which submitted lower densities. Nevertheless, the specimens with EVA1 residues on the 1:2:3 mix proportion presented sound pressure levels above the simple slab at frequencies of 125 and $160 \mathrm{~Hz}$, with the influence of the resonance frequency of the system.

In the third group, the sample with 1:1.5:3.5 (E2B) mix proportion presents a different behavior, as of $2000 \mathrm{~Hz}$ the specimens showed similar values to the second group. In

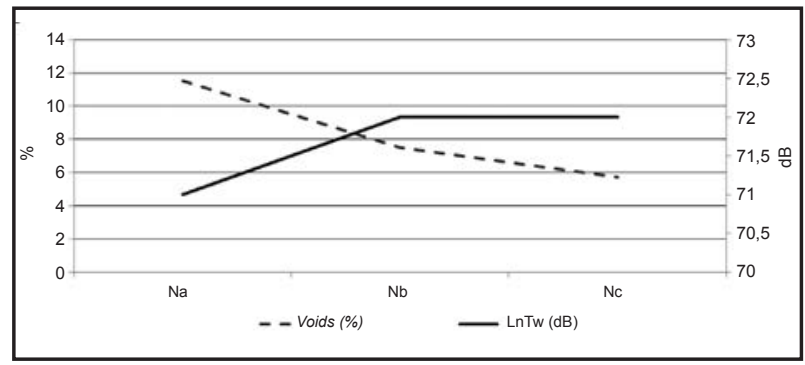

Figure 3. Relation between impact noise and voids: samples of natural course aggregate. general, the third group, using the EVA2 aggregate, gave intermediate results between the concrete and the reference EVA1.

The $L_{n T, w}^{\prime}$ values can be comparatively analyzed in Figure 2 , with the grouping by type of material composition of the specimens.

The samples made with natural coarse aggregate obtained values between 71 and $72 \mathrm{~dB}$, with a minimum performance rating for structural concrete slabs and off the minimum performance standards for affordable coverage, according Brazilian standard NBR 15575-3 (5). It is observed that the variation of the ratio coarse aggregate and fine aggregate had little influence on the final results. The samples with EVA1 showed greater variation, with values between 54 and $62 \mathrm{~dB}$, and only specimens with 1:1.5:3.5 mixture can be classified with superior performance. In the specimens prepared on the basis of EVA2 the results ranged from 56 to $62 \mathrm{~dB}$, with minimum performance rating for affordable roof terrace.

\subsection{Relation between impact noise and voids}

The test results of impact noise and amount of voids showed an inverse relation, as seen in Figures 3, 4 and 5. It can be said for the specimens studied in this article that the increase in amount of voids leads to better acoustic performance in slabs and toppings.

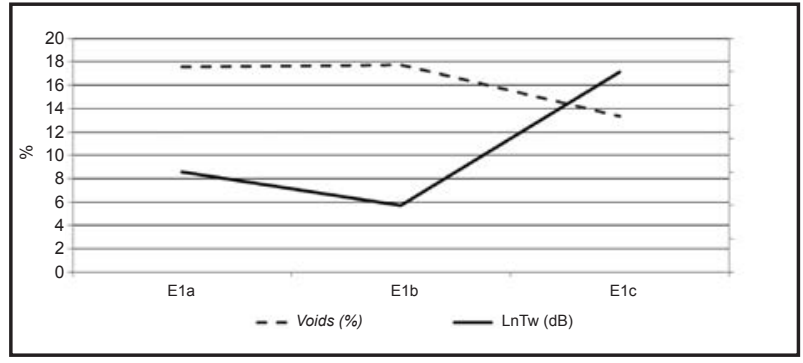

Figure 4. Relation between impact noise and voids: samples of EVA1 course aggregate. 


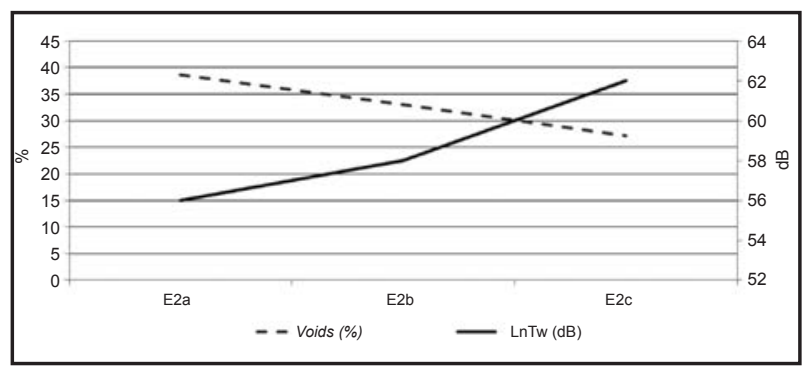

Figure 5. Relation between impact noise and voids: samples of EVA2 course aggregate.

\subsection{Relations between impact noise and real bulk density}

The relation between the impact noise level and bulk density showed a variation between the results of natural aggregate specimens and specimens with EVA. Most of the results show that the increase of the bulk density caused worse acoustic performance to the impact noise in the specimens studied. In specimens with natural aggregate the reduction in the proportion of coarse aggregate resulted in higher noise levels measured. However, the bulk density did not follow the same trend, with a reduction in value between $\mathrm{Nb}$ and Nc specimens, with $70 \%$ aggregate and $60 \%$ respectively (Figure 6).

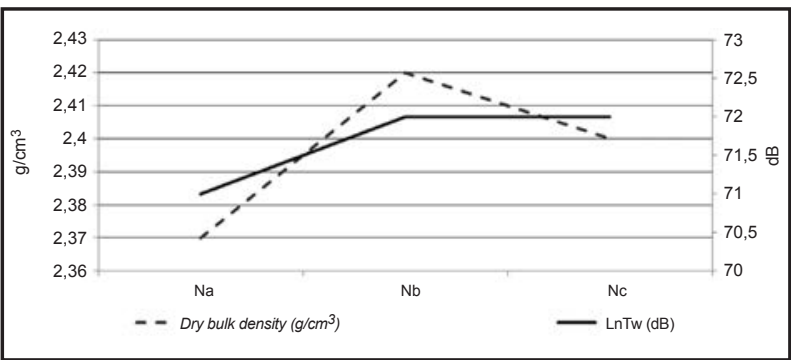

Figure 6. Relation between dry bulk density and impact noise levels: samples of natural course aggregate.
In samples with industrialized EVA residues the reduction in the proportion of coarse aggregate raised the values of dry density. However, changes in these proportions did not follow the same trend in noise levels measured, as it is observed in Figure 7.

The group of samples prepared with EVA residues obtained by means of recycling craft presented direct relation between the dry bulk density increases and noise levels measured. In Figure 8 these relations can be observed comparing the two upward graphs profiles, indicating that the increase in dry bulk density corresponds to an increase in noise levels measured. In these specimens group the increase in dry density and the reduction in the proportion of coarse aggregate contribute to the less performance of impact noise.

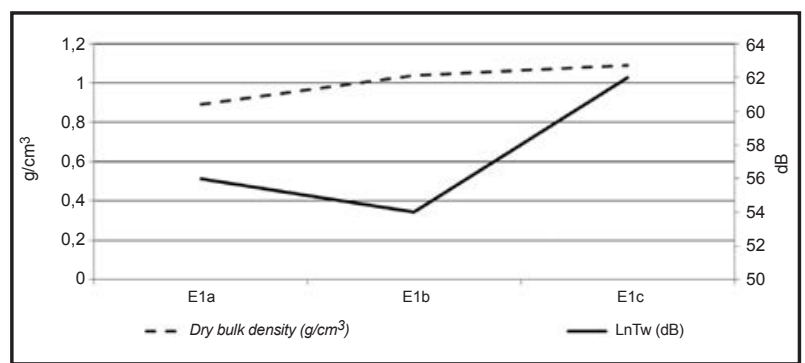

Figure 7. Relation between dry bulk density and impact noise levels: samples of EVA1.

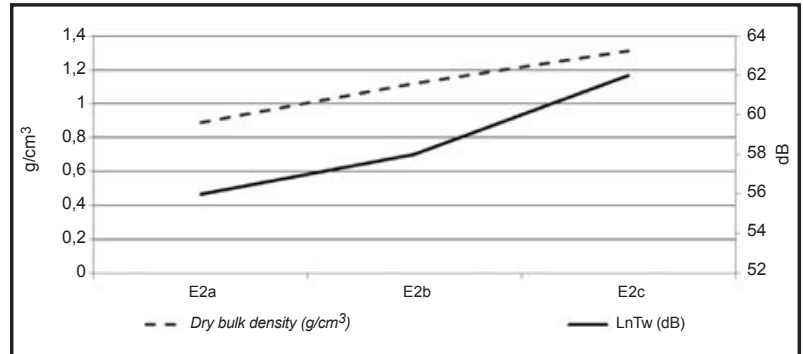

Figure 8. Relation between dry bulk density and impact noise levels: samples of EVA2. 


\section{CONCLUSIONS}

The concrete molded with EVA presented lower levels of bulk density of fresh concrete in comparison to the concretes with natural aggregates. It can be followed that the higher the percentage of lightweight aggregate added to the mix, the lower values of density.

In testing, the impact noise lightweight concrete achieved the best acoustic performance, with satisfactory performance for structural slabs. In the case of accessible coverage, the classification of acoustic performance decreased. However, other available coatings that can help with soundproofing should be considered for this kind of roof.

It was noted that the incorporation of EVA as resilient material on the sub floor could break the rigidity of floors in the system with efficiency. Furthermore, the use of material of different composition on the slab prevents the resonance effect of the system, which occurred by the presence of the natural aggregate both on the slab as in the samples with natural aggregate. However, it also shows that the highest percentage of coarse aggregate EVA does not increase the performance of acoustic noise impact. In the samples studied the reduction of $80 \%$ to $60 \%$ of coarse aggregate resulted in better acoustic performance, with $15 \mathrm{~dB}$ in noise levels reduction measured, from 77 $\mathrm{dB}$ to $62 \mathrm{~dB}$.

The relations obtained between the measured sound levels, voids and bulk density indicate that the major benefit in reducing the weight provided by the lightweight aggregate structures could be a higher acoustic quality in concrete floor.

\section{REFERENCIAS / REFERENCES}

(1) ISO 22966: 2009. "Execution of concrete structures".

(2) Pujolle, J.: La pratique de I'isolation acoustique des batiments, Moniteur, Paris (1978).

(3) Sancho, V. M.; Senchermes, A. G.: Acustica en arquitectura, Colegio Oficial de Arquitectos, Madrid (1982).

(4) Bistafa, S. R.: Acústica aplicada ao controle do ruído, Edgard Blücher, São Paulo (2006).

(5) ABNT NBR 15575-3: 2008. "Residential buildings up to five floors - Performance. Parte 3: Requisitos para os sistemas de pisos internos".

(6) Rushforth, I. M.; Horoshenkov, M.; Miraftab; Swift, M. J.: "Impact sound insulationand viscoelastic properties of underlay manufactured from recycled waste," Applied Acoustics, vol. 66 (2005), pp. 731-749. http://dx.doi.org/10.1016/j.apacoust.2004.10.005

(7) Pedroso, M. A. T.: Estudo comparativo entre modernas composições de pisos flutuantes, UFSM, Santa Maria (2007).

(8) Maderuelo-Sanz, R.; Martín-Castizo, M.; Vílchez-Gómez, R.: "The performance of resilient layers made from recycled rubber fluff for impact noise reduction," Applied Acoustics, vol. 72 (2011), pp. 823-828. http://dx.doi.org/10.1016/j.apacoust.2011.05.004

(9) Morais, L.; Pereira, A.; Godinho, L.: "Experimental characterization of the impact noise insulation of floating slab systems and floating floor system using a small footprint", X Encontro Nacional e VI Congresso Latinoamericano de Conforto no Ambiente Construído, Natal, ANTAC (2009), in CD-ROM.

(10) Nunes, M. F. O.; Rauber, J.: EVA waste material to reduce transmission of impact noise, São Paulo, EDUSP (2010).

(11) Nunes, M. F. O.; Andrde, M. Z.; Grisa, A. M. C.; Zattera, A. J.; Menegotto, A. N.: "Evaluation of polymeric material with waste in impact noise reduction on floors, XIII Encontro Nacional de Tecnologia no Ambiente Construído", Canela, ANTAC (2010), in CD-ROM.

(12) Hax, S. P. P.: Estudo do potencial de resíduos de EVA no isolamento do ruído de impacto em edificações, UFSM, Santa Maria (2002).

(13) ISO 6782: 1982. "Aggregates for concrete - Determination of bulk density".

(14) ISO 6274: 1980. "Concrete - Sieve analysis of aggregates".

(15) ISO 6783: 1982. "Coarse aggregates for concrete - Determination of particle density and water absorption - Hydrostatic balance method".

(16) ISO 140-7: 1998. "Acoustics: measurement of sound insulation in buildings and of buildings elements. Part 7: Field measurements of impact sound insulation of floors".

(17) ISO 717: 1996. "Acoustics: rating of sound insulation in buildings and of building elements. Part 2: Impact sound insulation".

(18) ISO 3310: 2000. "Test sieves - Technical requirements and testing".

(19) ISO 9597: 2008. "Cement - Test methods - Determination of setting time and soundness".

(20) ISO 1920: 2004. "Testing of concrete". 